\begin{tabular}{|c|c|}
\hline \multirow{3}{*}{ 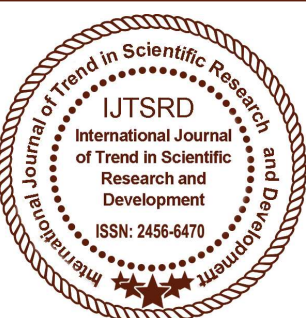 } & $\begin{array}{l}\text { International Journal of Trend in Scientific } \\
\text { Research and Development (IJTSRD) }\end{array}$ \\
\hline & International Open Access Journal \\
\hline & ISSN No: 2456 - 6470 | www.ijtsrd.com | Volume - 2 | Issue - 5 \\
\hline
\end{tabular}

\title{
Characterization of Polymer Composite Materials Based on Epoxy Resin GELR 128 Modified with Epoxidized Sunflower Oil Cured by 4.4'-Diaminodiphenylmethane
}

\author{
Bach Trong Phuc ${ }^{1}$, Vu Huu Hung ${ }^{2}$ \\ ${ }^{1}$ Associate Professor, Polymer Centre, Hanoi University of Science and Technology, Hanoi, Vietnam \\ ${ }^{2} \mathrm{PhD}$ Student, Ministry of Public Security, Hanoi, Vietnam
}

\begin{abstract}
Epoxidized sunflower oil (ESO) is used to modify the epoxy resin GELR 128 for increase the toughness of epoxy resin. ESO mixed with epoxy resin at different concentrations by one-stage and two-stage process. Epoxy resin GELR 128 and epoxidized sunflower oil were cured by aromatic amine curing agent (4.4'diaminodiphenylmethane (DDM)). Morphology, physicochemical, thermal properties of the epoxy resin GELR 128 after denaturation and curing indicated that the two-stage process is more better than the one-stage process which achieved by amount of ESO content is $15 \mathrm{phr}$ The best tensile strength, flexural strength, impact strength are 66.22 $\mathrm{MPa}, 81.7$ $\mathrm{MPa}, 32 \mathrm{~kJ} / \mathrm{m}^{2}$, and maximum decomposition temperature $394.550^{\circ} \mathrm{C}$.
\end{abstract}

Keywords: epoxy resin GELR 128, 4,4'diaminodiphenylmethane, epoxidized sunflower oil, toughness, high temperature curing.

\section{INTRODUCTION}

Epoxidized natural oil is one of the plasticizing agents for durability increase without sacrificing the thermal properties as well as the elasticity of the material [1]. Natural oils are one of the renewable material sources that are supplied from non-animal sources as well as from trees unlike other fossil fuels or petroleum. There are many types of natural oils that can be epoxidized, such as castor oil [2], palm [3], beans [4], coconut ... [5-7] Sunflower oil is one among the oils with superior advantages and simple epoxy treatment, cost savings, high epoxy performance. A sunflower oil molecule is up to 6 epoxy groups $[8,9]$. Especially when using sunflower oil as a second component for

phase separation when mixed with epoxy resin to increase toughness and durability without compromising the thermal properties as well as the elastic modulus of plastic [4,9]. Toughness is the ability of a material to absorb energy and plastically deform without fracturing [10]. The method for increasing epoxy resin toughness is achieved by reducing the cross-linking density of the plastic polymer circuit [11].

In the present study, we present the effects of epoxidized sunflower oil (ESO) content on the mechanical properties, thermal stability and morphological structure of epoxy resin GELR 128 modified with ESO cured by 4,4'diaminodiphenylmethane (DDM).

\section{Experimental}

\subsection{Materials}

Epoxy resin used in this study was DGEBA supplied by Epoxy Base Electronic Material Corporation Limited of China (GELR 128) which had an epoxide equivalent weight (EEW) of 184-190g eq-1 and a viscosity at 25oC: $11-15$ Pa.s;

Epoxidized sunflower oil (ESO) was synthesized by using ion exchange method. The content of epoxy group is $16.45 \%$ with oxiran value 6.12 .

4,4'-diaminodiphenyl-methane (DDM) was supplied from Aladdin Industrial Corporation Shanghai (China) (density $1.05 \mathrm{~g} / \mathrm{cm}^{3}$ at $100^{\circ} \mathrm{C}$, boiling point 398 to $399^{\circ} \mathrm{C}$, flash point $190^{\circ} \mathrm{C}$, melting point $89^{\circ} \mathrm{C}$ and molecular weight $198 \mathrm{~g} / \mathrm{mol}$ ). 


\subsection{Modified epoxy resins}

Modified epoxy resins were prepared by mixing DGEBA GELR 128 and epoxidized sunflower oil in two processes:

One-stage process: The various amount of ESO (030phr) was added into $100 \mathrm{~g}$ of epoxy resin GELR 128 in $250 \mathrm{ml}$ glass beakers, stirring for 45 minutes. Then DDM was added with a pre-calculated ratio and stirred for 5 minutes. The all components were poured into a mold for curing at $110^{\circ} \mathrm{C}$. . Two-stage process: Mixing ESO and DDM in a 3 necked 250-well flask were stirred for 20 hours, adding epoxy resin GELR 128 and continued stirring for 5 minutes and then poured the mixture into the mold to cure at $110^{\circ} \mathrm{C}$.

\subsection{Research Methods}

The morphologies at the fracture surfaces of the epoxy samples were evaluated from Scanning Electron Microscopy (SEM) on Hitachi (Japan) S4800 at the main laboratory, Institute of Materials Science Vietnam Academy of Science and Technology. Thermal stability was studied by simultaneous thermo gravimetric analyzer (TGA) by SETARAM TG under a heating rate of $10^{\circ} \mathrm{C} / \mathrm{min}$. within a temperature range of ambient room temperature to $800^{\circ} \mathrm{C}$ at Hanoi University of Sciences, Hanoi National University.
The tensile strength was determined according to ISO 527 - 2012 on the INSTRON 5582-100kN (USA) with the crosshead speed of $2 \mathrm{~mm} / \mathrm{min}$ at the Polymer Centre, Hanoi University of Science and Technology. The flexural strength was determined according to ISO 178 on the INSTRON $5528-100 \mathrm{kN}$ (USA) with the crosshead speed of $2 \mathrm{~mm} / \mathrm{min}$ at the Polymer Centre, Hanoi University of Science and Technology. Izod impact strength was determined according to ISO 180 on the Tinius Olsen Model 92T (USA) at the Polymer Centre, Hanoi University of Science and Technology. The critical stress intensity factor, $\mathrm{K}_{\mathrm{IC}}$ value was determined according to ASTM D5045- by three point sidedon a Lloyd 500N (UK) with the crosshead speed of $10 \mathrm{~mm} / \mathrm{min}$ at the Polymer Centre, Hanoi University of Science and Technology.

\section{Results and Discussion}

\subsection{Mechanical properties}

Epoxy resins are very useful in real life, but the disadvantage is their brittle properties. In this study we also investigated the effect of ESO content on the mechanical properties of epoxy/ESO composite samples by both one-stage process and two-stage process. The results are presented in Table 1.

Table 1: Influence of ESO content on tensile strength, elastic modulus, flexural strength, Kic coefficient of epoxy resin GELR 128 modified with ESO and cured by DDM

\begin{tabular}{|l|l|l|l|l|l|l|}
\hline \multicolumn{1}{|c|}{$\begin{array}{c}\text { ESO content } \\
(\mathrm{phr})\end{array}$} & $\begin{array}{c}\text { Tensile } \\
\text { strength } \\
(\mathrm{MPa})\end{array}$ & $\begin{array}{c}\text { Elongation } \\
\text { at break } \\
(\%)\end{array}$ & $\begin{array}{c}\text { Elastic } \\
\text { modulus } \\
(\mathbf{G P a})\end{array}$ & $\begin{array}{c}\text { Flexural } \\
\text { strength } \\
(\mathrm{MPa})\end{array}$ & $\begin{array}{c}\text { Flexural } \\
\text { strain } \\
(\%)\end{array}$ & $\begin{array}{c}\text { Flexural } \\
\text { modulus } \\
(\mathrm{GPa})\end{array}$ \\
\hline 0 & 83,4 & 5.33 & 1,94 & 128,8 & 5.2 & 3,9 \\
\hline 5 (in one-stage) & 76,55 & 5.59 & 1,79 & 117,7 & 5.6 & 3,27 \\
\hline (5) (in two-stage) & 73,55 & 6.38 & 1,69 & 94,1 & 5.7 & 3,13 \\
\hline 10 & 73,85 & 6.85 & 1,64 & 107,6 & 5.9 & 3,04 \\
\hline$(10)$ & 70,09 & 7.77 & 1,6 & 90,3 & 6.2 & 2,87 \\
\hline 15 & 73,02 & 7.69 & 1,64 & 90,5 & 6.5 & 2,89 \\
\hline$(15)$ & 66,22 & 9.15 & 1,54 & 81,7 & 7.8 & 2,77 \\
\hline 20 & 66,89 & 7.66 & 1,53 & 88,6 & 6.4 & 2,82 \\
\hline$(25)$ & 61,02 & 8.77 & 1,49 & 75,9 & 7.2 & 2,66 \\
\hline 30 & 51,75 & 5.84 & 1,33 & 75,7 & 5.7 & 2,55 \\
\hline$(30)$ & 47,61 & 7.59 & 1,28 & 67,6 & 6.6 & 2,27 \\
\hline
\end{tabular}

When increasing the ESO content from 0-30 phr, the tensile and flexural strength of the polymer composite sample tends to decrease in both one-stage process and two-stage process. This suggests that epoxy resin GELR 128 denaturation with ESO is more toughness than original GELR 128 epoxy resin [12]. The presence of ESO reduces the cross-linking density so that the epoxy resin becomes softer, the network structure is less rigid with increasing ESO content, so the flexural strength and modulus decrease [13, 14]. In both process, the mechanical properties of the epoxy resin GELR 128 after modification in the two- 
stage process were always lower at the various amount of ESO. Cause the large amount of epoxy group in ESO reacted to the amine group of curing agent before performed in a one-stage process. Epoxy resin GELR 128 cured by a two-stage process showed higher flexibility, suggesting a two-stage process for better response. Epoxy resins often have lower impact resistance $(19,817 \mathrm{~kJ} / \mathrm{m} 2)$ [15]. After being denatured with ESO, the impact strength of epoxy resin was higher than that of neat sample, as shown in Figure 1. The impact strength of the modified epoxy resin GELR 128 was higher than the unmodified epoxy resin GELR 128 in both one-stage process and two-stage process. However, the impact strength of the modified epoxy resin GELR 128 by one-stage process was only slightly increases and less than that in the two-stage process in various content of ESO.

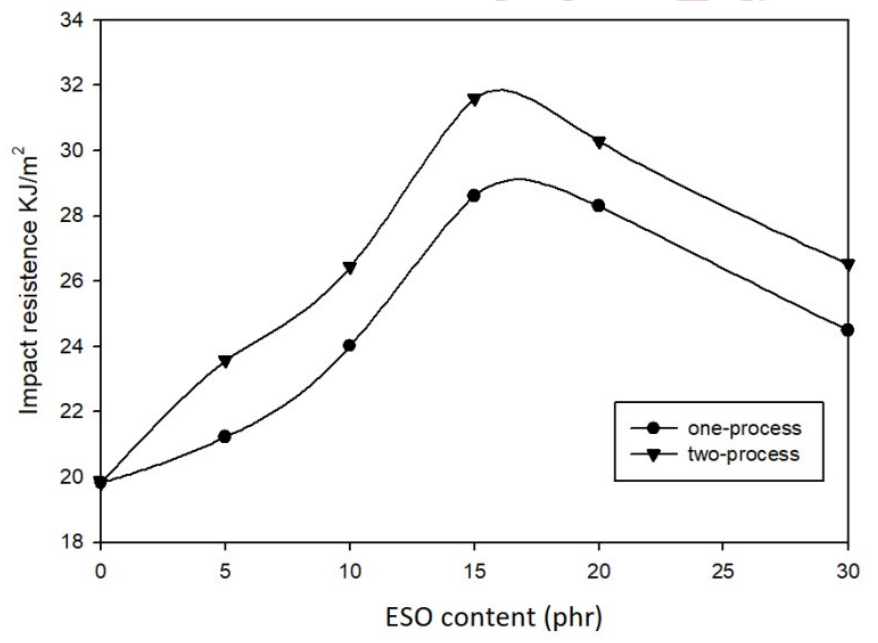

Figure 1: Effect of ESO content on impact strength of epoxy resin GELR 128 cured by DDM

From Fig. 1, it was found that when the ESO content was increased, the impact strength of the epoxy resin GELR 128 also increased, however, when increasing to $15 \mathrm{phr}$, the impact strength decreased sharply in both processes. From the results shown, it was found that the epoxy resin GELR 128 achieved the best impact strength when the ESO content was $15 \mathrm{phr}$. At the same time, the effect of ESO content on the impact strength of epoxy resin GELR 128 in both processes was found to be consistent with the twostage process and higher than in the one-stage process at all ESO content.

Figure 2 shows the influence of ESO content on the Kic coefficient to epoxy resin GELR 128 after denaturation. With low ESO $(<10$ phr $)$, the denaturation using both processes yield the same result. However, when the ESO content reached 15 phr, there was a significant difference in the epoxy resin GELR 128 residual effect coefficient which is higher in two-stage process. However a sharp decrease was observed in two-stage process.. Thus, the ESO content is 15 phr which gives the highest Kic coefficient of the denaturation epoxy resin GELR 128.

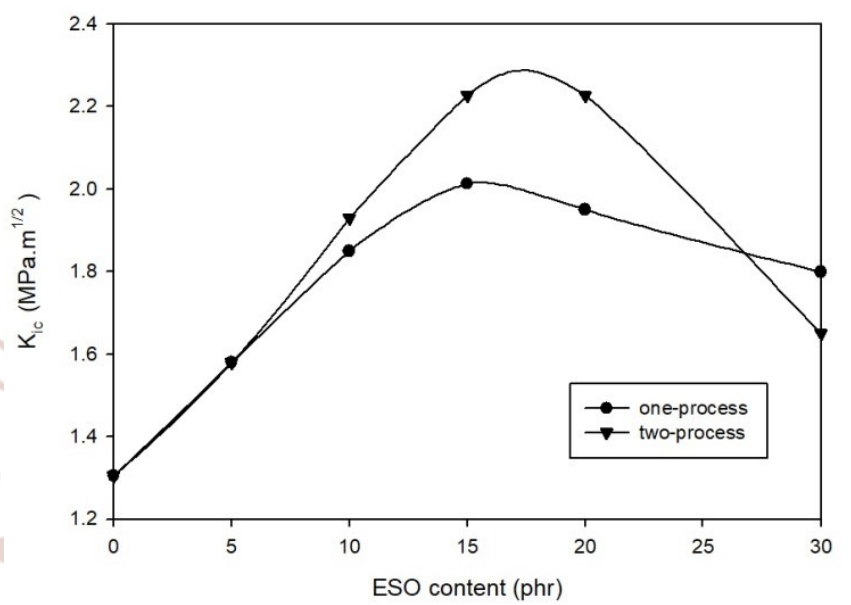

Figure 2: Effect of ESO content on Kic coefficient of epoxy resin GELR 128 cured by DDM

The research shows that with the two-stage process, the toughness of the epoxy resin GELR 128 has increased considerably with a nearly double impact resistance due to the one-stage process. The above results can be attributed to the following reasons: During the curing process ESO reacts with the DDM curing agent and then reacts and replaces the epoxy resin GELR 128. The added chemical activity groups (containing esters in the ESO oil circuit) were added to increase the plasticity of the epoxy resin GELR 128 , in addition, because ESO had a greater number of epoxy groups to increase the cross-linkage. Creates a three-dimensional network in the final curing [16, 17]. For two agents acting on this final product, the plasticization of the product increased significantly compared to the curing of the conventional epoxy resin. Although in both the one-stage process and two-stage process, curing was added to the ESO but during the two-stage process the amount of ESO was overweight. This is due to the fact that during mixing ESO reacts with DDM is more efficiently. In the twostage process, the ESO was more added due to the longer reaction time of DDM with ESO (10h) before being mixed with epoxy resin GELR 128. This increased the amount of vascular linkage as well as the chemical activity in the final product. The epoxy group at the beginning of the epoxy resin DGEBA reacts readily against DDM [18]. During one-stage process, DDM will preferentially react with epoxy 
resin DGEBA first and then react further with ESO. The combined ESO throughout the system will decrease due to the cumbersome distribution of DGEBA - DDM epoxy space. Therefore, the number of link vessels and chemical activity groups will not be added to the optimum amount, which will also affect the plasticity of the material. As the results, the two-stage process has advantages over the one-stage process.

\subsection{Morphological structure}

Scanning electron microscopy (SEM) of the nondenaturing epoxy resin GELR 128 and using modified ESO with a content of solid $15 \mathrm{phr}$ by DDM is shown in Figure 3. From Figure 3 (a), it was found that the non-denaturing epoxy resin GELR 128 with a fractured surface with cracks in different surfaces characterized by poor impact strength of the thermoplastic resin. For epoxy resin GELR 128 denatured by ESO, the image of surface fracture is no longer smooth (compare Figure 3a with Figures $3 \mathrm{~b}$ and $3 \mathrm{c}$ ), resulting in rugged spots and no longer classified as Non-denatured epoxy resin. From the SEM image (Fig. 3b), the distribution of the surface image of the "archipelagic" product structure with the "round islands" is the ESO structural droplets that help plasticize the epoxy resin GELR 128 well distribution in material, and inherent hardware of epoxy resin (sea water). As the presence of ESO droplets, the plasticity of the epoxy resin GELR 128 has been strengthened as a result of the mechanical properties described above [19]. Combined with the results of the above physico-chemical properties, the incorporation of ESO changed the physical and morphological characteristics of the epoxy resin GELR 128. The rugged image of the SEM (Fig 3c) shows epoxy resin GELR 128 after denaturation is more flexible than non-denatured epoxy resin GELR 128 when cured with DDM under the same conditions and only difference by the two-stage process.

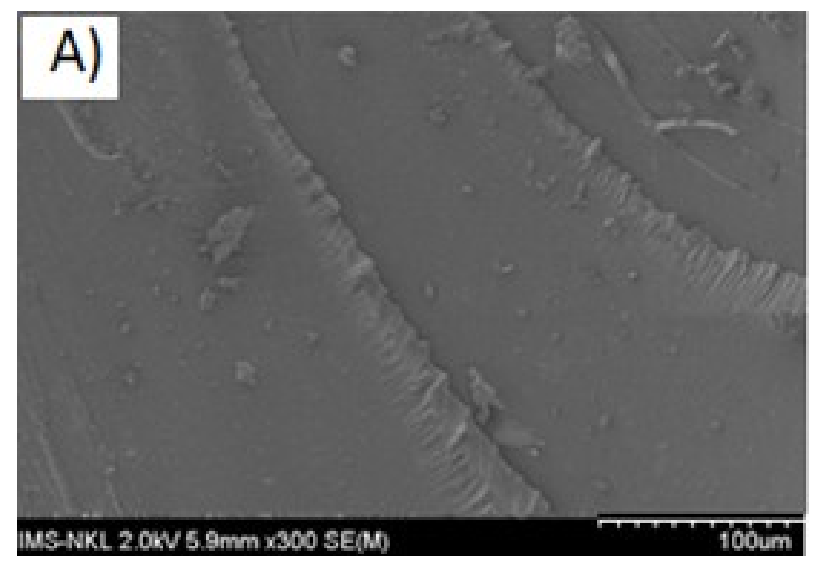

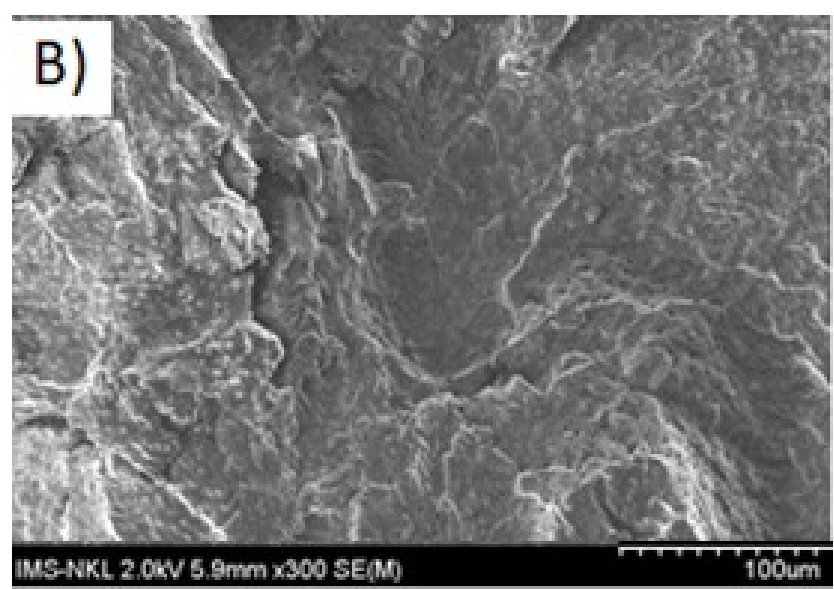

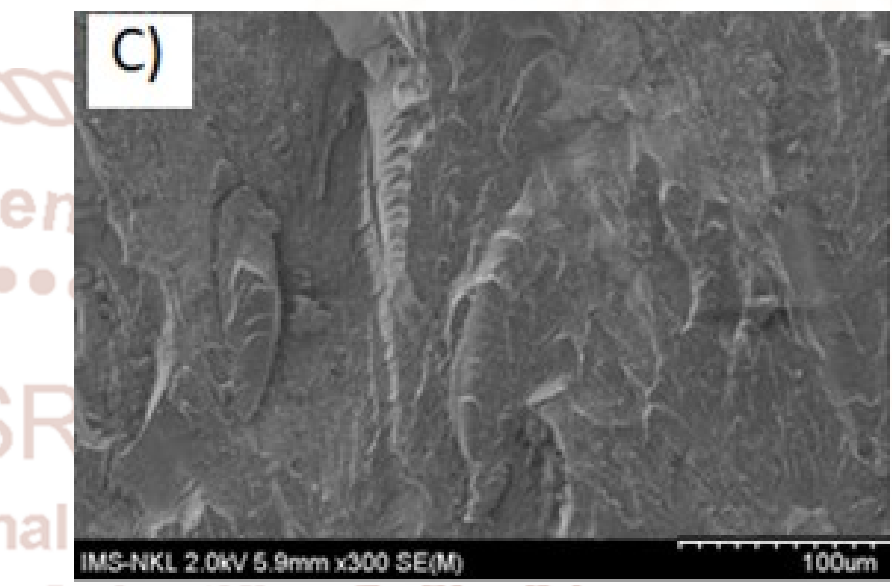

Figure 3: SEM images of fracture surface of cured epoxy resin GELR 128 (a) without ESO; (b) one-stage process with $15 \mathrm{phr}$ of ESO; c) two-stage process with $15 \mathrm{phr}$ of ÉO.

\subsection{Thermal properties}

From Table 2 and Figure 4 it can be seen that, when adding ESO content to the denaturation of epoxy resin GELR 128, the maximum decomposition temperature of the epoxy resin GELR 128 varies with two different trends, increasing in the two-stage process and a slight down turn in the one-stage process. This demonstrates that during the first stage, the reaction does not occur with optimal efficiency. In the twostage of reaction, the highest decomposition temperature was $397.95^{\circ} \mathrm{C}$. From the results of the survey, it was found that the simultaneous use of ESO and application during the two-stage process resulted in a better thermal property of the epoxy resin GELR 128 , increasing the thermal stability of the epoxy resin GELR 128. 
Table 2: Effect of ESO content on the maximum decomposition temperature of epoxy resin GELR 128 cured by DDM

\begin{tabular}{|c|c|c|}
\hline No. & ESO content (phr) & $\begin{array}{c}\text { Maximum } \\
\text { decomposed } \\
\text { temperature }\left({ }^{\circ} \mathrm{C}\right)\end{array}$ \\
\hline 1 & 0 & 394.31 \\
\hline 2 & 15 (one-stage process) & 392.48 \\
\hline 3 & 15 (two-stage process) & 397.95 \\
\hline
\end{tabular}
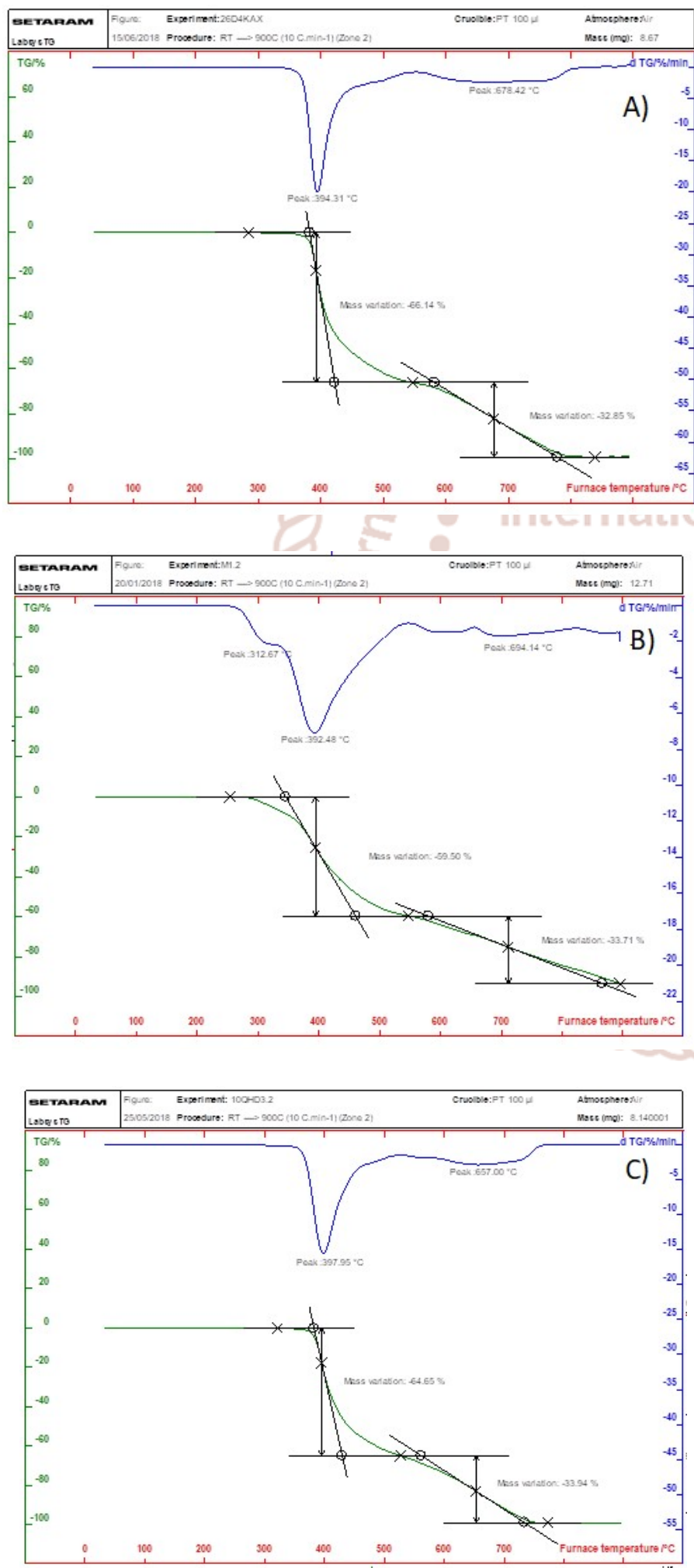

Figure 4: TGA thermograms of a) epoxy resin GELR 128 b) epoxy resin GELR 128 modified with ESO in one-stage process c) epoxy resin GELR 128 modified with ESO in two-stage process.

\section{Conclusion}

The influence of epoxidized sunflower oil as a stabilizer for the the polymer composite materials based on epoxy resin GELR 128 cured by DDM was studied in two processes: one-stage process and twostage process at high temperature. The epoxy resin GELR 128 modified with $15 \mathrm{phr}$ of ESO in both two processes: one-stage process and two-stage process cured by DDM had more tough than neat epoxy resin GELR 128. For the two-stage process, the cured epoxy resin GELR 128 had the better thermal properties than cured epoxy resin GELR 128 in onestage process with the same content of ESO (15 phr).

\section{REFERENCES}

1. Zhou, H. and S. Xu, "A new method to prepare rubber toughened epoxy with high modulus and high impact strength". Materials Letters,vol. 121, 2014, pp. 238-240.

2. Park, S.J., F.L. Jin, and J.R. Lee,"Effect of biodegradable epoxidized castor oil on physicochemical and mechanical properties of epoxy resins". Macromolecular Chemistry and Physics,vol. 205, 2004, pp 2048-2054.

3. Chieng, B.W., et al., "Graphene nanoplatelets as novel reinforcement filler in poly (lactic acid)/epoxidized palm oil green nanocomposites", Mechanical properties. International journal of molecular sciences, vol 13. 2012.pp 10920-10934.

4. Ratna, D., "Mechanical properties and morphology of epoxidized soyabean-oil-modified epoxy resin" Polymer international, vol 20, 2001. pp. 179-184.

5. Tan, S. and W. Chow, "Biobased epoxidized vegetable oils and its greener epoxy blends" A review. Polymer-Plastics Technology and Engineering, vol 49. 2010. pp. 1581-1590.

6. Jian, X.-Y., et al., "Curing of epoxidized soybean oil with crystalline oligomeric poly(butylene succinate) towards high performance and sustainable epoxy resins". Chemical Engineering Journal, vol 326. 2017. pp. 875-885.

7. Park, S.-J., F.-L. Jin, and J.-R. Lee, "Thermal and mechanical properties of tetrafunctional epoxy resin toughened with epoxidized soybean oil". 
Materials Science and Engineering: A, vol 374. 2004.pp. 109-114.

8. Benaniba, M.T., N. Belhaneche-Bensemra, and G. Gelbard, "Kinetics of tungsten-catalyzed sunflower oil epoxidation studied by1H NMR" European Journal of Lipid Science and Technology, vol 109. 2007. pp. 1186-1193.

9. BROWN, S.C.K.H.R., "Impact-modified epoxy resin with glassy second component". JOURNAL OF MATERIALSSCIENCE, vol 22. 1987. pp. 2589-2594.

10. Ratna, D., R. Varley, and G. Simon, "Processing and chemorheology of epoxy resins and their blends with dendritic hyperbranched polymers". Journal of applied polymer science, vol 92. 2004. pp. 1604-1610.

11. Yang, J.-P., et al., "Superiority of nanosized over microsized hyperbranched polymer second phase in modifying brittle epoxy resin". Journal of Applied Polymer Science, vol 119.2011.pp. 863 870.

12. Sprenger, S., "Epoxy resins modified with elastomers and surface-modified silica nanoparticles".Polymer, vol 54. 2013. pp. 47904797.

13. Zeng, R.-T., et al., "Curing behavior of epoxidized soybean oil with biobased dicarboxylic acids". Polymer Testing, vol 57. 2017. pp. 281-287.
14. Chen, Y., Z. Xi, and L. Zhao, "New bio-based polymeric thermosets synthesized by ring-opening polymerization of epoxidized soybean oil with a green curing agent". European Polymer Journal, vol 84. 2016. pp. 435-447.

15. Banthia2*, D.R.a.A.K., "Toughened epoxy adhesive modified with acrylate based liquid rubber". Polymer International, vol 49. 2000. pp. 281-287.

16. Ehlers, J.-E., et al., "Theoretical study on mechanisms of the epoxy- amine curing reaction". Macromolecules. Vol 40. 2007. pp. 4370-4377.

17. Kaynak, C., A. Ozturk, and T. Tincer, "Flexibility improvement of epoxy resin by liquid rubber modification". Polymer international, vol 51. 2002. pp. 749-756.

18. Hodgkin, J., G. Simon, and R.J. Varley, "Thermoplastic toughening of epoxy resins: a critical review". Polymers for advanced technologies, vol 9. 1998. pp. 3-10.

19. Chen, Z.-K., et al., "Reinforcement of epoxy resins with multi-walled carbon nanotubes for enhancing cryogenic mechanical properties" Polymer, vol 50. 2009. pp. 4753-4759. 